\title{
Effects of Early and Late Bilingualism on Resting-State Functional Connectivity
}

\author{
Jonathan A. Berken, ${ }^{1,2}$ Xiaoqian Chai, ${ }^{1}$ Jen-Kai Chen, ${ }^{1}$ Vincent L. Gracco, ${ }^{2,3}$ and Denise Klein ${ }^{1,2}$ \\ ${ }^{1}$ Cognitive Neuroscience Unit, Montreal Neurological Institute, Montreal, Quebec H3A 2B4, Canada, ${ }^{2}$ Centre for Research on Brain, Language, and Music, \\ McGill University, Montreal, Quebec H3G 2A8, Canada, and ${ }^{3}$ Haskins Laboratories, New Haven, Connecticut 06511
}

Of current interest is how variations in early language experience shape patterns of functional connectivity in the human brain. In the present study, we compared simultaneous (two languages from birth) and sequential (second language learned after age 5 years) bilinguals using a seed-based resting-state MRI approach. We focused on the inferior frontal gyrus (IFG) as our ROI, as recent studies have demonstrated both neurofunctional and neurostructural changes related to age of second language acquisition in bilinguals in this cortical area. Stronger functional connectivity was observed for simultaneous bilinguals between the left and right IFG, as well as between the inferior frontal gyrus and brain areas involved in language control, including the dorsolateral prefrontal cortex, inferior parietal lobule, and cerebellum. Functional connectivity between the left IFG and the right IFG and right inferior parietal lobule was also significantly correlated with age of acquisition for sequential bilinguals; the earlier the second language was acquired, the stronger was the functional connectivity. In addition, greater functional connectivity between homologous regions of the inferior frontal gyrus was associated with reduced neural activation in the left IFG during speech production. The increased connectivity at rest and reduced neural activation during task performance suggests enhanced neural efficiency in this important brain area involved in both speech production and domain-general cognitive processing. Together, our findings highlight how the brain's intrinsic functional patterns are influenced by the developmental timeline in which second language acquisition occurs.

Key words: bilingualism; brain development; early experience; inferior frontal gyrus; language; resting-state functional connectivity

\section{Significance Statement}

Of current interest is how early life experience leaves its footprint on brain structure and function. In this regard, bilingualism provides an optimal way to determine the effects of the timing of language learning because a second language can be learned from birth or later in life. We used resting-state fMRI to look at simultaneous and sequential bilinguals who differed only in age of acquisition, and found stronger connectivity between language and cognitive control regions in bilinguals who learned their two languages simultaneously, a pattern that was associated with more efficient brain activation during speech. Our findings highlight how functional connections in the brain differ depending upon when learning takes place.

\section{Introduction}

Brain development is influenced substantially by early life experience (Kolb et al., 1998; Neville and Bavalier, 2002). Although

\footnotetext{
Received May 20, 2015; revised Dec. 1, 2015; accepted Dec. 9, 2015.

Author contributions: J.A.B., J.-K.C., V.L.G., and D.K. designed research; J.A.B. and X.C. performed research; J.A.B., X.C., V.L.G., and D.K. analyzed data; J.A.B., V.L.G., and D.K. wrote the paper.

This work was supported by the Blema and Arnold Steinberg Family Foundation and the Natural Sciences and Engineering Research Council of Canada to D.K. and V.L.G., the Social Sciences and Humanities Research Council of Canada to Shari R. Baum, V.L.G., and D.K., and a Vanier Canada Doctoral Scholarship to J.A.B. We thank Jennifer Soles who assisted with the experimental setup and subject recruitment; and Megan Callahan who assisted with the quantitative language assessment.

The authors declare no competing financial interests.

Correspondence should be addressed to Dr. Jonathan A. Berken, Cognitive Neuroscience Unit, Montreal Neurological Institute, 3801 University Street, Room 264, Montréal, QC H3A 2B4, Canada. E-mail: jonathan.berken@gmail.com.

DOI:10.1523/JNEUROSCI.1960-15.2016

Copyright $\odot 2016$ the authors $\quad 0270-6474 / 16 / 361165-08 \$ 15.00 / 0$
}

behavioral studies have described an optimal period for language acquisition (Penfield and Roberts, 1959; Lenneberg, 1967; Flege et al., 1999; Moyer et al., 2007), the lasting effects of early language exposure on brain organization remain to be determined. Bilingualism is a useful model to examine the neural changes that occur during development because second language (L2) proficiency can be attained from infancy to adulthood. Neuroimaging studies have suggested that second language expertise engages a network of cortical and subcortical brain regions, and the maturation of these areas is shaped by the timing of language learning (Klein et al., 1994, 1995, 2006, 2014; Berken et al., 2015a, b). Studies of brain trauma, indeed, have shown that children who sustain focal brain injury in the perinatal period can overcome their deficits, whereas adults often cannot, suggesting that brain reorganization is greatest when language learning occurs early in development (Bates, 1999). 
Early experience with a second language appears to play a particularly significant role in the development of the inferior frontal gyrus (IFG) (Wartenburger et al., 2003; Klein et al., 2014; Berken et al., 2015a). In a recent study, Klein et al. (2014) measured cortical thickness in early and late bilinguals and showed that later L2 acquisition was associated with thicker cortex in the left IFG and thinner cortex in the right IFG. Within the bilingual group, a significant positive correlation between age of L2 acquisition (AoA) and cortical thickness in the left IFG and a negative correlation in the right IFG was observed, consistent with patterns of functional lateralization in bilingual adults (Hull and Vaid, 2006, 2007). Nevertheless, language processing requires coordinated interactions among distributed brain regions, and it is likely that an early language experience would also shape the connectivity profile of the IFG. In other words, acquiring a second language very early versus later in life might result in differences in neural circuitry involving the IFG because dual language input from birth occurs while neural networks are developing. In contrast, late L2 learning takes place after these networks are already established, thereby relying on the modification of existing circuitry. In support of this view, research on lexical development suggests that how the brain is programmed for a second language depends in large part on the neural scaffolding established during L1 acquisition (Hernandez et al., 2005; Hernandez and Li, 2007; Hernandez, 2013). In this way, the effects of age of acquisition on brain development may reflect the degree to which the first language has been established when the L2 is learned, rather than the actual chronological time point during which the onset of L2 learning occurs.

In the present study, we compare simultaneous (two languages acquired from birth) and sequential bilinguals (L2 learned after age 5 years) using a seed-based resting-state fMRI (rs-fMRI) approach, with the IFG selected as our ROI. rs-fMRI is a particularly effective tool to examine the cumulative effects of language experience on the functional organization of the human brain because the technique is not constrained by a given experimental paradigm. Rather, rs-fMRI derives functional connectivity between anatomically separated brain areas by identifying spontaneous, correlated low-frequency BOLD signal fluctuations in the brain that occur in the absence of task-driven behavior (Biswal et al., 1995, 1997; Fox and Raichle, 2007; Lewis et al., 2009; Smith et al., 2013). By exploring IFG connectivity in bilinguals who differ only in AoA, we can uncover neuroplastic changes that might explain the efficient speech processing ability of early bilinguals, and shed light on the effects of early experience on the organizational patterns of the brain's language network.

\section{Materials and Methods}

Participants. Sixteen French-English simultaneous bilinguals (two languages acquired from birth; 6 males and 10 females) and 18 sequential bilinguals (L2 learned after the age of 5 years; 10 males and 8 females) participated in this study. Simultaneous bilinguals considered themselves equally dominant in both English and French, having learned one language from each parent. Sequential bilinguals were either English (L1)-French (L2) or French (L1)-English (L2).

Before scanning, participants were assessed to be healthy, without hearing or reading impairment, neurological disorder, or history of brain trauma. Individuals who self-reported a high degree of musical skill were excluded, given the link between musical training and language ability (Schön et al., 2004) and the plastic effects of musical experience on brain organization (Gaser and Schlaug, 2003). Multilinguals were also excluded. Equivalent nonverbal intelligence was determined between groups using the Block Design Subtest of the Wechsler Abbreviated Scale of Intelligence (Table 1) (Wechsler, 1981). Bilinguals were recruited from
Table 1. Subject demographics ${ }^{a}$

\begin{tabular}{lll}
\hline & Simultaneous $(N=16)$ & Sequential $(N=18)$ \\
\hline Gender (male/female) & $6 / 10$ & $10 / 8$ \\
Chronological age (years) & $23.3(3.1)$ & $25.7(4.5)$ \\
L2 age of acquisition (years) & $0(0)$ & $13.5(6.4)^{b}$ \\
Formal education (years) & $16.1(2.7)$ & $17.3(3.1)$ \\
WASI block design (1-19) & $13.6(1.6)$ & $13.4(2.4)$ \\
\hline
\end{tabular}

${ }^{a}$ Values are mean (SD).

${ }^{b}$ Range: 5 -26 years.

Table 2. Self-reported language assessment (LEAP-Q) ${ }^{a}$

\begin{tabular}{lccccc}
\hline & \multicolumn{2}{l}{ Simultaneous $^{b}$} & & \multicolumn{2}{l}{ Sequential } \\
\cline { 2 - 3 } \cline { 6 - 6 } & L1-French & L1-English & & L1 & L2 \\
\hline \% exposure & $37.3(15.4)$ & $60.5(16.9)$ & & $62.2(17.1)$ & $37.3(16.9)$ \\
Speaking $^{c}$ & $8.9(1.2)$ & $9.1(1.1)$ & & $9.4(0.92)$ & $7.5(1.5)$ \\
Listening $^{c}$ & $9.6(0.62)$ & $9.6(0.89)$ & & $9.7(0.67)$ & $8.1(1.3)$ \\
Reading $^{c}$ & $9.4(0.51)$ & $9.6(0.62)$ & & $9.6(0.70)$ & $7.9(1.1)$ \\
\hline
\end{tabular}

Values are mean (SD).

${ }^{b}$ Subjects were equally dominant in French and English.

${ }^{c} 1$ = low proficiency; $10=$ high proficiency.

the McGill University community and gave informed consent. Testing procedures were approved by the Research Ethics Board of the Montreal Neurological Institute, Montreal, Quebec, Canada.

Language proficiency assessment. All bilingual subjects were determined to be highly proficient and were exposed to and use French and English on a daily basis (Table 2). A qualitative Language Experience and Proficiency Questionnaire (LEAP-Q) (Marian et al., 2007) was first administered. Simultaneous and sequential bilinguals reported a high level of proficiency in their two languages (Table 2).

To quantify language proficiency, recordings of all bilingual subjects producing speech were obtained in French and English. Participants were asked to provide a spontaneous speech sample for $2 \mathrm{~min}$ in each language describing either a typical day at the beach or at the zoo. Instructions were delivered in the language required for the response. Subjects were instructed to create the most relevant story that came to mind. Spectrograms were generated for each sample using Praat software (Boersma, 2001), and speech was then evaluated using the Compleat Lexical Tutor (Cobb, 2009), an automated pipeline, for (a) lexicosemantics, number of unique and total words; (b) complexity of syntax; and (c) speech fluency, words per minute (Berken et al., 2015a). Scoring by this algorithm was then checked for accuracy by manual inspection.

To establish an accent score for each subject in their two languages, three English and three French native speakers, unfamiliar with the objectives of the study, evaluated the recorded speech on a 7 point scale for the degree to which subjects sounded native-like $(1=$ very poor/trés faible; 7 = native-like/langue maternelle). Results were assessed for interrater reliability in French and English ( $\alpha=0.92$ and 0.80 , respectively) and averaged across raters within each language, which provided accent scores for each subject in both languages.

Resting-state $f M R I$. Participants were instructed to relax and fixate on a cross that was presented visually on a screen in the scanner. For the resting-state fMRI analysis, data were acquired using a $\mathrm{T}_{2}{ }^{*}$-weighted EPI sequence with the following parameters: $\mathrm{TR}=2210 \mathrm{~ms}$; $\mathrm{TE}=30 \mathrm{~ms}$; matrix size $=64 \times 64 ; \mathrm{FOV}=224 \mathrm{~mm}$; flip angle $=90^{\circ}$; slice thickness $=$ $3.5 \mathrm{~mm}$; and axial slices $=42$. A total of 136 volumes were obtained in 5 min $9 \mathrm{~s}$. For all subjects, high-resolution $\mathrm{T}_{1}$-weighted images obtained from a 3D Magnetization Prepared Rapid Gradient Echo (MP-RAGE) sequence were used as anatomical references $(\mathrm{TR}=23 \mathrm{~ms}$; $\mathrm{TE}=2.98 \mathrm{~ms}$; slice thickness $=1 \mathrm{~mm}$; image matrix $=256 \times 256$; flip angle $=30^{\circ}$; $\mathrm{FOV}=256 \mathrm{~mm}$; interleaved excitation).

Resting-state fMRI analyses were performed using a seed-driven approach with the CONN software package (Chai et al., 2012; WhitfieldGabrieli and Nieto Castanon, 2012). The left and right IFG pars triangularis (IFGpt), BA 45 were chosen as ROI according to the Automated Anatomical Labeling atlas (Tzourio-Mazoyer et al., 2002), as these 
areas have emerged from recent functional (Klein et al., 1995, 2006; Berken et al., 2015a) and structural (Klein et al., 2014; Berken et al., 2015b) neuroimaging studies as loci particularly involved in bilingual language processing. Cognizant of the recent interest in subregion specialization of the inferior prefrontal cortex, however, we also selected seeds from the left and right IFG pars opercularis (IFGpo), BA 44, and the left and right IFG pars orbitalis, BA 47.

The data were first preprocessed using standard spatial preprocessing steps, including slice-time correction, realignment, coregistration to structural, normalization, and smoothing with a $5 \mathrm{~mm}$ Gaussian kernel. Spurious correlations in resting-state networks caused by head motion were corrected by identifying problematic time points during the scan using Artifact Detection Tools (ART, www.nitrc.org/projects/artifact_detect/). Images were determined to be outliers if the head displacement in the $x, y$, or $z$ directions was $>0.5 \mathrm{~mm}$ from the previous frame, or if the rotational displacement was $>0.02$ radians from the previous frame, or if the global mean intensity in the image was $>3$ SDs from the mean image intensity for the entire resting scan. Outlier images were not deleted from the time series but rather modeled in the first-level GLM. Therefore, the temporal structure of the data was not disrupted. Each outlier was represented by a single regressor in the GLM, with a 1 for the outlier time point and 0 elsewhere.

Physiological and other spurious sources of noise were estimated and regressed out using the anatomical CompCor method (aCompCor) (Behzadi et al., 2007), which reduces motion-related artifacts in resting-state data (Muschelli et al., 2014). Global signal regression, a widely used preprocessing method that may introduce biases in results (Murphy et al., 2009; Saad et al., 2012; McAvoy et al., 2015), was not used. On the basis of previous results (Chai et al., 2012), five principal components of the signals from WM and CSF noise ROIs were removed with regression. A temporal bandpass filter of $0.009-0.08 \mathrm{~Hz}$ was applied to the time series. Residual head motion parameters (three rotation and three translation parameters, plus another six parameters representing their firstorder temporal derivatives) were regressed out. The simultaneous and sequential bilingual groups did not significantly differ in average rotation ( $p=0.85)$, average translation $(p=0.45)$, or the absolute number of outliers $(p=0.92)$.

First-level correlation maps were produced by extracting the residual BOLD time course from the left and right IFG seeds (i.e., BA 44, 45, and 47) and computing Pearson's correlation coefficients between that time course and the time course of all other voxels. Correlation coefficients were converted to normally distributed $z$ scores using the Fisher transformation to allow for second-level GLM analyses. Two sample $t$ tests were performed to directly compare the connectivity maps between simultaneous and sequential bilinguals, where chronological age was included in the model as a variable of noninterest. In addition, regression analyses of age of acquisition were performed within the sequential bilingual group, with chronological age incorporated into the design as a covariate of noninterest.

fMRI analysis of speech production. All simultaneous bilinguals and a subset of the sequential bilinguals (i.e., 13 of the 18 subjects scanned for the resting-state study) were previously investigated using a task-based paradigm in which participants read simple, meaningful sentences aloud in English and French in the scanner (Berken et al., 2015a) that were composed of high-frequency items and matched for number of syllables and grammatical tense. Strings of XXX were visually presented on the screen as a control baseline.

Task-based fMRI data acquisition. Participants were scanned at the Montreal Neurological Institute on a 3T Siemens Magnetom Trio A Tim System. High-resolution $\mathrm{T}_{1}$-weighted images were obtained as anatomical references using a 3D MP-RAGE sequence $(\mathrm{TR}=23 \mathrm{~ms}$; $\mathrm{TE}=2.98$ $\mathrm{ms}$; slice thickness $=1 \mathrm{~mm}$; image matrix $=256 \times 256$; flip angle $=30^{\circ}$; $\mathrm{FOV}=256 \mathrm{~mm}$; interleaved excitation). Each sentence was presented for $7750 \mathrm{~ms}$ followed by the $2210 \mathrm{~ms}$ whole-brain acquisition. Functional images for the sentence reading tasks were acquired with $\mathrm{T}_{2}{ }^{*}$-weighted gradient echo EPI sequence $\left(3.5 \times 3.5 \times 3.5 \mathrm{~mm}^{3}\right.$ voxel size; flip angle $=$ $90^{\circ}$; echo time $=30 \mathrm{~ms}$; repetition time $=9960 \mathrm{~ms}$; silent interval $=7790$ $\mathrm{ms}$; interleaved excitation) with 42 oblique slices $\left(30^{\circ}\right.$ off the anteriorposterior commissural plane).
Table 3. Analysis of spontaneous speech ${ }^{a}$

\begin{tabular}{|c|c|c|c|c|}
\hline & \multicolumn{2}{|c|}{ Simultaneous $^{b}$} & \multicolumn{2}{|l|}{ Sequential } \\
\hline & L1-French & L1-English & L1 & L2 \\
\hline \multicolumn{5}{|l|}{ Lexicosemantics } \\
\hline No. of unique words & $130.0(22.4)$ & $134.3(15.2)$ & $134.7(24.6)$ & $113.4(27.2)$ \\
\hline No. of total words & 310.5 (71.6) & $304.4(41.8)$ & $313.4(59.4)$ & $265.2(64.9)$ \\
\hline \multicolumn{5}{|l|}{ Syntax } \\
\hline$\%$ complex sentences & $36.3(14.7)$ & $40.2(14.8)$ & $39.3(20.1)$ & $37.4(15.9)$ \\
\hline Speech fluency & & & & \\
\hline Words per minute & $155.1(35.9)$ & $152.2(20.9)$ & $156.7(29.7)$ & $132.6(32.4)$ \\
\hline Phonology & & & & \\
\hline Accent (rating 1-7) & $5.4(1.1)$ & $5.8(0.88)$ & $6.1(0.87)$ & $4.3(1.3)^{*}$ \\
\hline
\end{tabular}

${ }^{a}$ Values are mean (SD).

${ }^{b}$ Subjects were equally dominant in French and English.

*Significance $(p<0.05)$.

Statistical analyses of task-based fMRI data. A standard fMRI analysis method using fMRIstat was used to process the data (for details on fMRI analysis, see Berken et al., 2015a) that included a principal component analysis and motion correction and a whole-brain regression analysis in all bilinguals (simultaneous and sequential) with age of acquisition. A significant positive relationship between AoA and BOLD signal in the left IFG (BA 45) during English sentence reading was found for all bilinguals. English was a native language for the simultaneous bilinguals and a nonnative language for the sequential bilinguals, given that all of the simultaneous bilinguals acquired both English and French from birth and the subset of sequential bilinguals from our previous fMRI study of speech production included here all acquired French as their first language and English as their second language.

Correlation between task-based and resting-state fMRI. In the present study, we explore the relationship between task-based and resting-state fMRI by computing a Pearson correlation coefficient between the degree of IFGpt functional connectivity and the extent of BOLD activation in the left IFGpt during English sentence reading.

\section{Results}

\section{Quantitative language assessment}

Simultaneous and sequential bilinguals were highly proficient in both languages, although sequential bilinguals produced speech with a more native-like accent in their L1 than L2 $\left(t_{(34)}=4.56\right.$; $p=0.0001)$. Simultaneous bilinguals' speech in French and English was also significantly more native-sounding than the sequential bilinguals' speech in L2 $\left(t_{(32)}=3.67 ; p=0.009 ; t_{(32)}=2.47\right.$; $p=0.019$, respectively). No other significant within- or betweengroup behavioral difference was found (Table 3). It should be noted that there were no proficiency differences among sequential bilinguals related to whether French or English was the L1, and results from the language proficiency assessment are therefore presented in terms of the L1 and L2.

\section{Left and right IFGpt seed regions: group comparison}

Within the language network, the IFG plays a significant role in speech production and language processing, as well as in nonlinguistic domain-general cognitive processes, such as executive control. Here, simultaneous bilinguals demonstrated stronger functional connectivity between the left inferior frontal seed and its homolog, the right IFGpt, as well as with the right IFGpo, right dorsolateral prefrontal cortex, and bilateral inferior parietal lobule than sequential bilinguals (Fig. 1a; Table 4).

Simultaneous bilinguals also demonstrated stronger restingstate functional connectivity between the right IFG seed and its homolog, the left IFGpt, as well as with the left IFGpo, and bilateral posterior cerebellum, than sequential bilinguals (Fig. $1 b$; Table 4). 
a
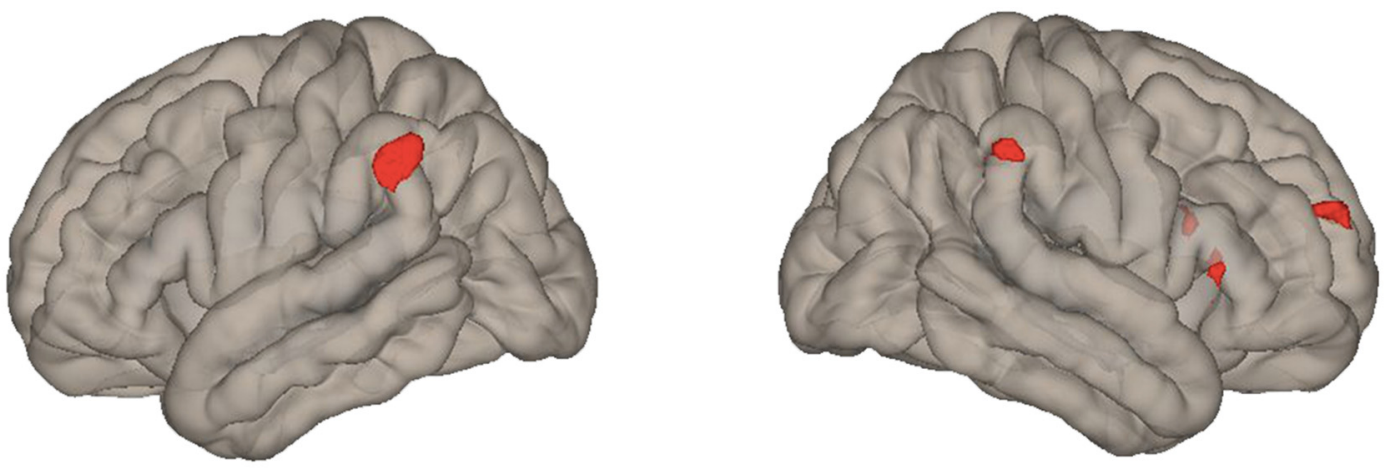

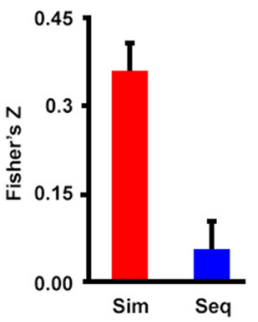

Left IPL

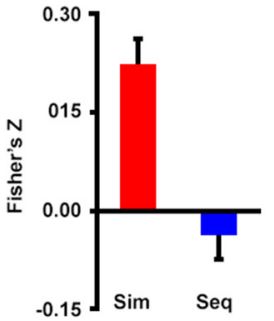

Right IPL

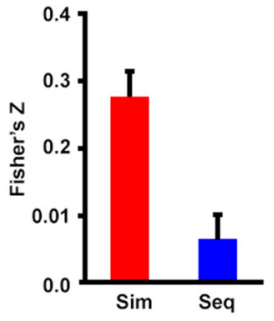

Right IFG

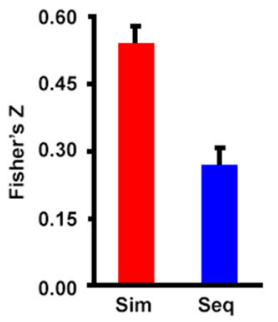

Right IFG (pars opercularis)

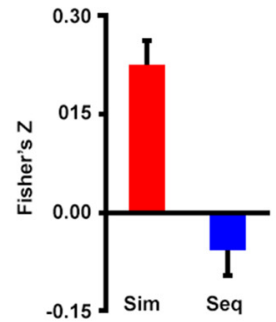

Right DLPFC

b
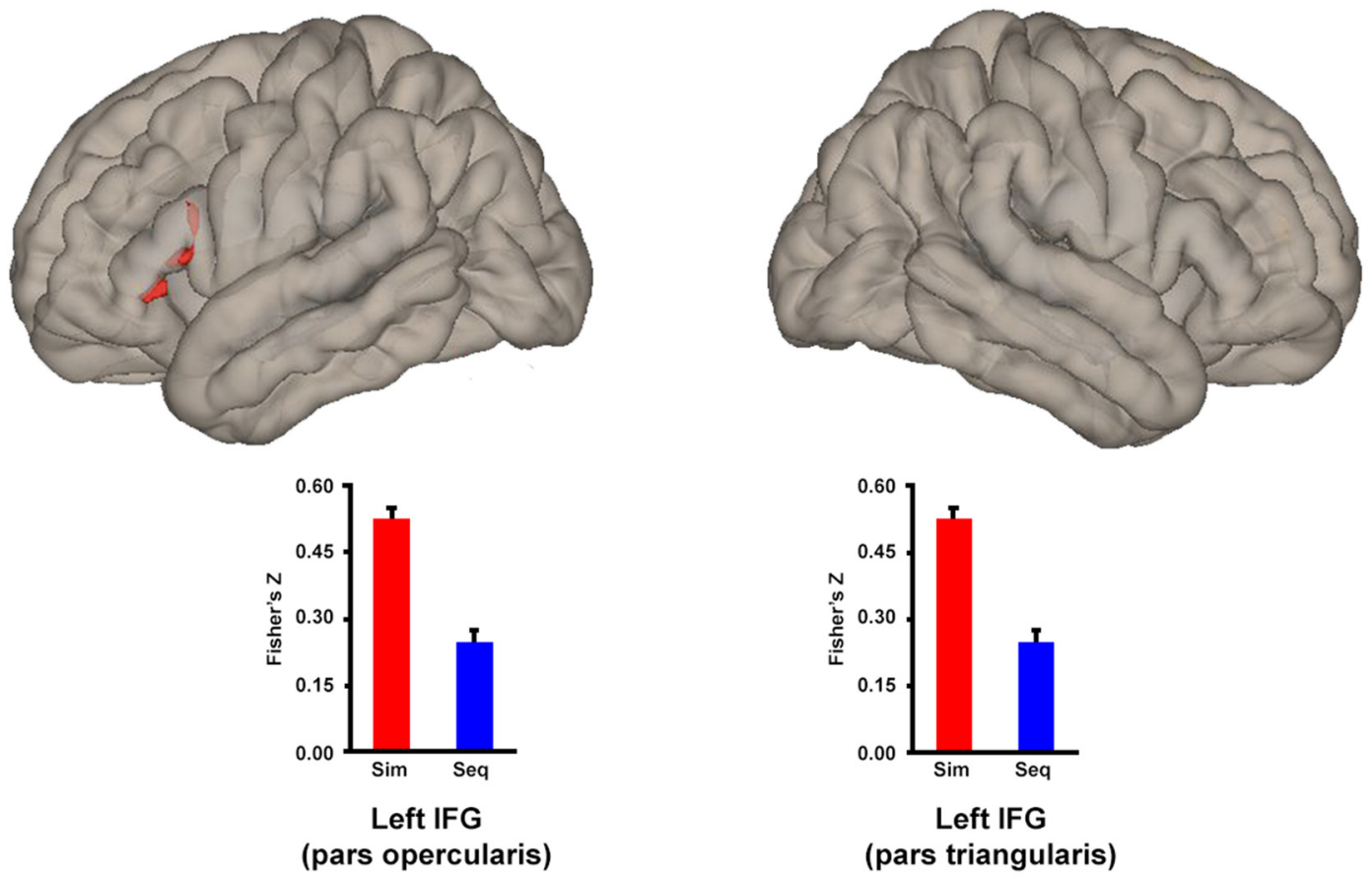

Figure 1. Significant correlations in functional connectivity overlaid on the surface of a standardized brain indicating group differences. Correlation coefficients converted to normally distributed z scores using the Fisher transformation for the Simultaneous (Sim) and Sequential (Seq) bilingual groups are displayed for the left (a) and right ( $\boldsymbol{b}$ ) IFGpt seeds. Histograms and scatter plots represent mean connectivity between the seed region and each cluster. Error bars indicate SEM. Clusters survived a height threshold of uncorrected $p<0.001$ and an extent threshold of FWE-corrected $p<0.05$ at the cluster level.

\section{Left IFGpt seed region: regression analysis with age of} acquisition in sequential bilinguals

For sequential bilingual subjects, a significant negative correlation with age of acquisition between the left inferior frontal seed and its homolog, the right IFGpt $(x=60 ; y=32 ; z=16$; $r=-0.640 ; p=0.000149 ; k=2263)$, as well as with the right inferior parietal lobule $(x=68 ; y=-46 ; z=38 ; r=-0.723 ; p=$ $0.0180 ; k=1120$ ) was demonstrated (Fig. 2). That is, the earlier the age at which a second language is acquired, the greater is the resting-state connectivity between the left inferior frontal seed and the right inferior frontal and right inferior parietal regions.

IFGpo and pars orbitalis seed regions: group comparison and regression analyses

No group differences in resting-state connectivity nor correlations with age of acquisition were observed for either the left or 
Table 4. Group comparison: simultaneous > sequential

\begin{tabular}{|c|c|c|c|c|c|c|}
\hline \multirow[b]{2}{*}{ Brain area } & \multicolumn{3}{|l|}{ Left IFGpt seed } & \multicolumn{3}{|l|}{ Right IFGpt seed } \\
\hline & $x, y, z$ & $p$ & $k$ & $x, y, z$ & $p$ & $k$ \\
\hline \multicolumn{7}{|l|}{ Left hemisphere } \\
\hline IFGpt (BA 45) & - & - & - & $-54,20,6$ & 0.000678 & 70 \\
\hline IFGpo (BA 44) & - & - & - & $-58,16,18$ & 0.000678 & 50 \\
\hline $\begin{array}{l}\text { Inferior parietal lobule } \\
\text { (BA 40) }\end{array}$ & $-62,-50,38$ & 0.000289 & 189 & - & - & - \\
\hline Posterior cerebellum & - & - & - & $-24,-74,-28$ & 0.000017 & 279 \\
\hline Right hemisphere & & & & & & \\
\hline $\begin{array}{l}\text { Dorsolateral prefrontal } \\
\text { cortex (BA 9) }\end{array}$ & $30,54,22$ & 0.007779 & 103 & - & - & - \\
\hline IFGpt (BA 45) & $52,24,8$ & 0.018005 & 71 & - & - & - \\
\hline IFGpo (BA 44) & $50,16,18$ & 0.018005 & 74 & - & - & - \\
\hline $\begin{array}{l}\text { Inferior parietal lobule } \\
\qquad(\mathrm{BA} 40)\end{array}$ & $70,-34,38$ & 0.018005 & 72 & - & - & - \\
\hline Posterior cerebellum & & & & $36,-86,-32$ & 0.019758 & 87 \\
\hline
\end{tabular}

right IFGpo seed regions. Similarly, no group differences in resting-state connectivity nor correlations with age of acquisition were observed for either the left or right IFG pars orbitalis seed regions.

\section{Relationship between functional connectivity strength and neural activation during speech production}

A significant negative correlation was found between restingstate functional connectivity of the left and right IFGpt and BOLD activation in the left IFGpt during English sentence reading for all bilinguals (Pearson's $r=-0.438$; $p=0.018$; Fig. 3 ). That is, the greater was the interhemispheric connectivity between the left and right IFGpt, the lower the neural activation in the left IFGpt was required for speech in English. English was a native language for the simultaneous bilinguals and a non-native language for the sequential bilinguals.

Although a significant correlation between resting-state and task-based functional activation was demonstrated for the entire group of bilingual subjects, only a trend was observed in this regard within the sequential bilingual group (Pearson's $r=-0.356 ; p=0.12$ ).

\section{Discussion}

The aim of the present study was to investigate whether an early versus late second language experience would be associated with different patterns of functional connectivity. We focused on the IFG as our ROI, as recent studies have demonstrated both neurofunctional and neurostructural changes related to age of acquisition in bilinguals in this cortical area (Wartenburger et al., 2003; Klein et al., 2014; Berken et al., 2015a). For example, Klein et al. (2014) found thinner cortex in the left IFG and thicker cortex in the right IFG for early bilinguals, indicating that patterns of brain organization differ depending on whether a second language is acquired before or after the closing of a sensitive period for language development. Further, early bilinguals have shown greater bihemispheric involvement than late L2 learners, who rely more significantly on the dominant left hemisphere to manage their two languages (Hull and Vaid, 2006, 2007).

Here, simultaneous bilinguals evidenced greater functional connectivity between the left and right IFG than did sequential bilinguals, with the degree of connectivity correlating significantly and negatively with AoA in sequential bilinguals. This pattern is supported by ontogenic studies showing early maturation of interhemispheric connections subserving anterior brain regions (Giedd et al., 1996), and suggests that dual language input from birth might have trophic effects on these connections during development. Although changes in connectivity between left and right anterior language regions still occur when a second language is learned in adulthood (Schlegel et al., 2012), such alterations might be optimized by simultaneous bilingual acquisition.

Previous studies have implicated the right IFG as central to response inhibition and attentional control (Dove et al., 2000; Hampshire and Owen, 2006; Hampshire et al., 2010), acting as a brake to slow, pause, or completely suppress a behavioral response (Aron et al., 2004, 2014). The right IFG plays a domaingeneral role in this regard, a function that, although language nonspecific (Vigneau et al., 2011), is likely essential for bilinguals to navigate a complex linguistic environment characterized by distinct semantic, syntactic, and phonological cues. Indeed, evidence suggests that damage to the right IFG, especially the pars triangularis region, disrupts appropriate response selection (Aron et al., 2003).

With regard to the left IFG, Coderre et al. (2015) found significant functional overlap in the domains of linguistic executive control, nonlinguistic executive control, and language processing within the left IFG BA 45/47, suggesting interdependence between the executive and language control systems. Greater functional connectivity between the left and right IFG might allow simultaneous bilinguals to more efficiently regulate two competing language systems, perhaps through greater suppression of the nontarget language (Green, 1998) or through more effective interactions between cognitive control areas required for L2 speech production (Hernandez et al., 2015). This view is further supported by observations that sustained bilingual attention recruits bihemispheric prefrontal regions involved in executive control (Wang et al., 2009).

In contrast, for sequential bilinguals, a lesser degree of interhemispheric functional connectivity appears to be compensated for by heightened activation of the left hemisphere during speech production. We found previously more robust activation of the left IFG when sequential bilinguals read sentences aloud in their L2 (Berken et al., 2015a). Here, we found a significant negative correlation between resting-state functional connectivity and BOLD signal change in the left IFGpt induced by performance of this task, suggesting a functional consequence of decreased bilateralization for late L2 learners. Thus, our results not only corroborate previous reports showing that spontaneous brain activity is predictive of neurofunctional outcomes (Mennes et al., 2010; Ventura-Campos et al., 2013) but also indicate the ways in which brain organization is modified by the age at which the bilingual experience begins.

In addition to the more synchronous activity between the left and right IFGpt, simultaneous bilinguals had greater connectivity between the IFGpt and a distributed system of cognitive control areas, including the dorsolateral prefrontal cortex and inferior parietal lobule, within the frontoparietal executive control circuit (Cole and Schneider, 2007; Vincent et al., 2008; Spreng et al., 2010; Wang et al., 2014; Behroozmand et al., 2015), a system of brain regions that manages cognitive function across a wide array of conditions and facilitates rapid changes in behavior that require enhanced attention. García-Pentón (2013) recently identified increased efficiency of the frontoparietal subnetwork for early Spanish-Basque bilinguals, and there is emerging evidence that this control system persists in older bilingual adults (Grady et al., 2015). We also noted increased functional connectivity for simultaneous bilinguals between the IFGpt and the posterior cerebellum, a region implicated in linguistic control and conflict 

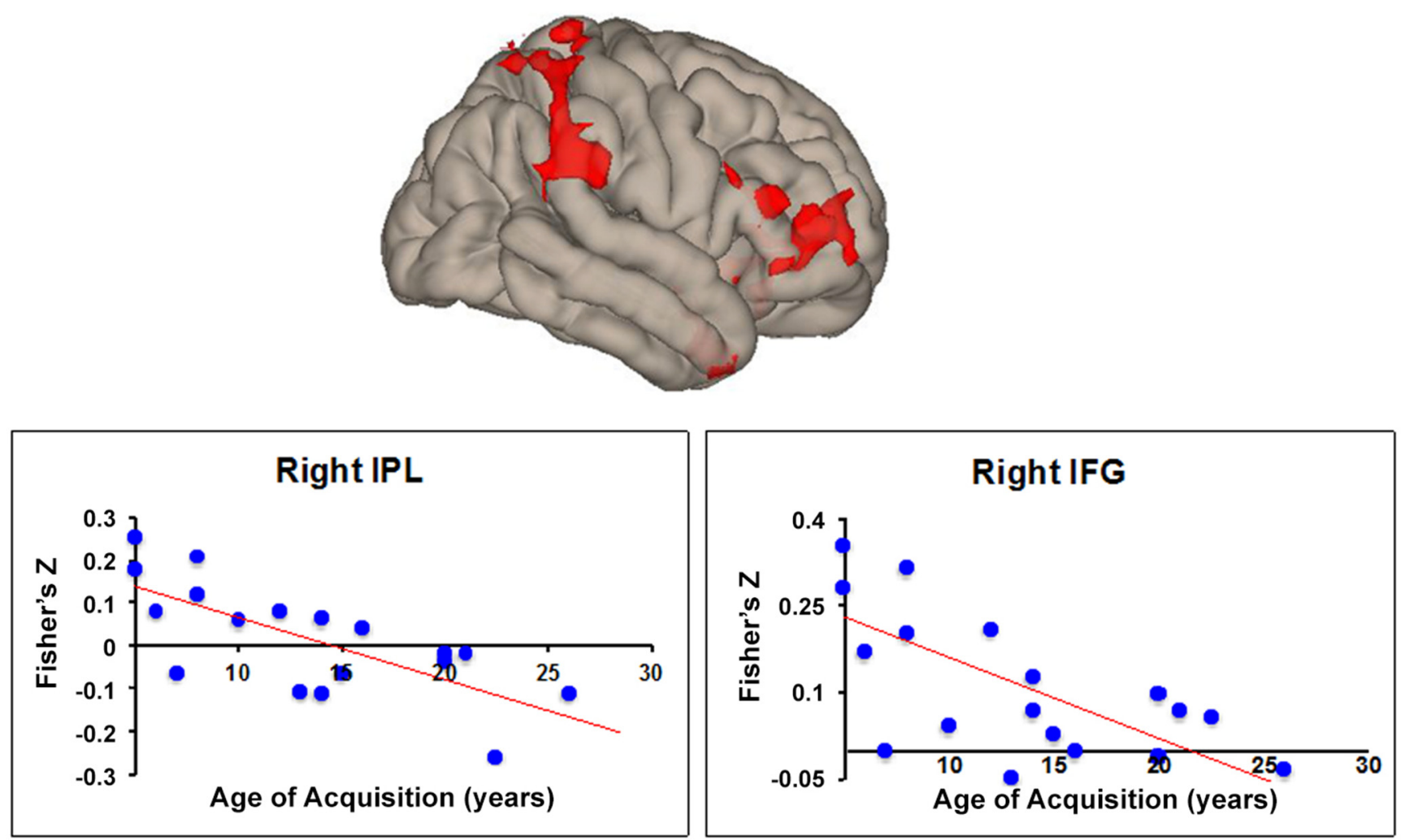

Figure 2. Functional connectivity related to age of acquisition in sequential bilinguals overlaid on the surface of a standardized brain. A significant negative correlation between resting-state functional connectivity in the left IFGpt seed region and age of acquisition was observed for sequential bilinguals. Scatter plots represent mean connectivity between the seed region and each cluster. Error bars indicate SEM. Clusters survived a height threshold of uncorrected $p<0.05$ and an extent threshold of FWE-corrected $p<0.05$ at the cluster level.

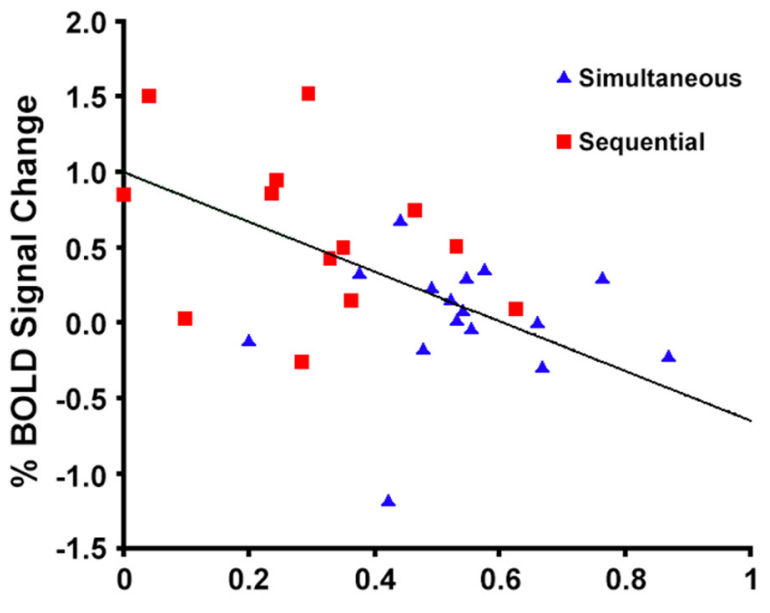

Fisher's Z

Figure 3. A significant negative correlation was determined between interhemispheric connectivity strength of the IFGpt and neural activation in the left IFG during speech production for simultaneous and sequential bilinguals. Here, the stronger the functional connectivity between the left and right IFG, the lower the functional activation of the left IFG is required to achieve proficient speech.

monitoring (Filippi et al., 2011), which plays a role in phonetic timing, auditory signal segregation, motor articulation and perception, and temporal coordination of high-level language functions (Callan et al., 2007; Stoodley et al., 2012). Thus, simultaneous bilingual acquisition might favor stronger, and perhaps more efficient, language control networks to optimize language processing. Interestingly, these findings were true only for the pars triangularis region (BA 45) and not for the pars opercularis (BA 44) or pars orbitalis (BA 47) regions. The patterns of functional segregation of the IFG may reflect stronger connections between brain areas related to domain-general executive control and language processing (i.e., BA 45), an observation consistent with previous reports investigating prefrontal cortex involvement in complex cognitive processing (Jeon and Friederici, 2005) and response inhibition and attentional control (Aron et al., 2003).

In conclusion, the results of the present study provide clear evidence that, in the bilingual brain, the degree of functional connectivity within the language control network is shaped by age of $\mathrm{L} 2$ acquisition. These observations, coupled with data from a task-related fMRI investigation with these same bilingual subjects (Berken et al., 2015a), imply that early second language proficiency and efficiency are influenced by both local, interhemispheric, and distributed, anteroposterior brain connections. The observed increase in connectivity between language and cognitive control regions in simultaneous compared with sequential bilinguals may reflect a greater ability among early bilinguals to meet the control demands of speaking two languages, offering a possible explanation for the apparent advantage of early bilinguals in dual language processing. In contrast, individuals who learn a second language later in life use different functional circuitry to attain second language expertise, as evidenced by greater left lateralization of the IFG. Together, our findings provide further support that the brain is shaped differentially depending on the period in development in which second language acquisition occurs. Future studies should help determine whether these differences in functional connectivity are accompanied by anatomical changes in white matter microstructure. 


\section{References}

Aron AR, Fletcher PC, Bullmore ET, Sahakian BJ, Robbins TW (2003) Stopsignal inhibition disrupted by damage to right inferior frontal gyrus in humans. Nat Neurosci 6:115-116. CrossRef Medline

Aron AR, Robbins TW, Poldrack RA (2004) Inhibition and the right inferior frontal cortex. Trends Cogn Sci 8:170-177. CrossRef Medline

Aron AR, Robbins TW, Poldrack RA (2014) Inhibition and the right frontal cortex: one decade on. Trends Cogn Sci 18:177-185. CrossRef Medline

Bates E (1999) Plasticity, localization and language development. In: The changing nervous system: neurobehavioral consequences of early brain disorders (Broman S, Fletcher JM, eds), pp 214-253. New York: Oxford UP.

Behroozmand R, Shebek R, Hansen DR, Oya H, Robin DA, Howard MA 3rd, Greenlee JD (2015) Sensory-motor networks involved in speech production and motor control: an fMRI study. Neuroimage 109:418-428. CrossRef Medline

Behzadi Y, Restom K, Liau J, Liu TT (2007) A component based noise correction method (CompCOr) for BOLD and perfusion based fMRI. Neuroimage 37:90-101. CrossRef Medline

Berken JA, Gracco VL, Chen JK, Watkins KE, Baum S, Callahan M, Klein D (2015a) Neural activation in speech production and reading aloud in native and non-native languages. Neuroimage 112:208-217. CrossRef Medline

Berken JA, Gracco VL, Chen JK, Klein D (2015b) The timing of language learning shapes brain structure associated with articulation. Brain Struct Funct. Advance online publication. Retrieved Sep 29, 2015.

Biswal BB, Van Kylen J, Hyde JS (1997) Simultaneous assessment of flow and BOLD signals in resting-state functional connectivity maps. NMR Biomed 10:165-170. CrossRef Medline

Biswal B, Yetkin FZ, Haughton VM, Hyde JS (1995) Functional connectivity in the motor cortex of resting human brain using echo-planar MRI. Magn Reson Med 34:537-541. CrossRef Medline

Boersma P (2001) Praat, a system for doing phonetics by computer. Glot Int 5:341-345.

Callan DE, Kawato M, Parsons L, Turner R (2007) Speech and song: the role of the cerebellum. Cerebellum 6:321-327. CrossRef Medline

Chai XJ, Castañón AN, Ongür D, Whitfield-Gabrieli S (2012) Anticorrelations in resting state networks without global signal regression. Neuroimage 59:1420-1428. CrossRef Medline

Cobb T (2009) The Compleat Lexical Tutor. www.lextutor.ca. Accessed September 18, 2012.

Coderre EL, Smith JF, van Heuven WJB, Horwitz B (2015) The functional overlap of executive control and language processing in bilinguals. Bilingualism Lang Cogn. Available on CJO 2015. doi:10:1017/ S13667289150000188.

Cole MW, Schneider W (2007) The cognitive control network: integrated cortical regions with dissociable functions. Neuroimage 37:343-360. CrossRef Medline

Dove A, Pollmann S, Schubert T, Wiggins CJ, von Cramon DY (2000) Prefrontal cortex activation in task switching: an event-related fMRI study. Brain Res Cogn Brain Res 9:103-109. CrossRef Medline

Filippi R, Richardson FM, Dick F, Leech R, Green DW, Thomas MS, Price CJ (2011) The right posterior paravermis and the control of language interference. J Neurosci 31:10732-10740. CrossRef Medline

Flege J, Yeni-Konshian G, Liu S (1999) Age constraints on second-language acquisition. J Mem Lang 41:78-104. CrossRef

Fox MD, Raichle ME (2007) Spontaneous fluctuations in brain activity observed with functional magnetic resonance imaging. Nat Rev Neurosci 8:700-711. CrossRef Medline

García-Pentón L, Pérez Fernández A, Iturria-Medina Y, Gillon-Dowens M, Carreiras M (2014) Anatomical connectivity changes in the bilingual brain. Neuroimage 84:495-504. CrossRef Medline

Gaser C, Schlaug G (2003) Brain structures differ between musicians and non-musicians. J Neurosci 23:9240-9245. Medline

Giedd JN, Rumsey JM, Castellanos FX, Rajapakse JC, Kaysen D, Vaituzis AC, Vauss YC, Hamburger SC, Rapoport JL (1996) A quantitative MRI study of the corpus callosum in children and adolescents. Dev Brain Res 91:274-280. CrossRef Medline

Grady CL, Luk G, Craik FI, Bialystok E (2015) Brain network activity in monolingual and bilingual older adults. Neuropsychologia 66:170-181. CrossRef Medline
Green DW (1998) Mental control of the bilingual lexico-semantic system. Bilingualism Lang Cogn 1:67-81. CrossRef

Hampshire A, Owen AM (2006) Fractionating attentional control using event-related fMRI. Cereb Cortex 16:1679-1689. CrossRef Medline

Hampshire A, Chamberlain SR, Monti MM, Duncan J, Owen AM (2010) The role of the right inferior frontal gyrus: inhibition and attentional control. Neuroimage 50:1313-1319. CrossRef Medline

Hernandez AE (2013) What factors influence how two languages are coded in one brain: comment on "The bilingual brain: flexibility and control in the human cortex" by Buchweitz and Prat. Phys Life Rev 10:450-451. CrossRef Medline

Hernandez AE, Li P (2007) Age of acquisition: its neural and computational mechanisms. Psychol Bull 133:638-650. CrossRef Medline

Hernandez A, Li P, MacWhinney B (2005) The emergence of competing modules in bilingualism. Trends Cogn Sci 9:220-225. CrossRef Medline

Hernandez AE, Woods EA, Bradley KA (2015) Neural correlates of single word reading in bilingual children and adults. Brain Lang 143:11-19. CrossRef Medline

Hull R, Vaid J (2006) Laterality and language experience. Laterality 11: 436-464. CrossRef Medline

Hull R, Vaid J (2007) Bilingual language lateralization: a meta-analytic tale of two hemispheres. Neuropsychologia 45:187-2008. CrossRef Medline

Jeon HA, Friederici AD (2013) Two principles of organization in the prefrontal cortex are cognitive hierarchy and degree of automaticity. Nat Commun 4:2041-2048. CrossRef Medline

Klein D, Zatorre RJ, Milner B, Meyer E, Evans AC (1994) Left putaminal activation when speaking a second language: evidence from PET. Neuroreport 5:2295-2297. CrossRef Medline

Klein D, Milner B, Zatorre RJ, Meyer E, Evans AC (1995) The neural substrates underlying word generation: a bilingual functional imaging study. Proc Natl Acad Sci U S A 92:2899-2903. CrossRef Medline

Klein D, Watkins KE, Zatorre RJ, Milner B (2006) Word and nonword repetition inbilingual subjects: a PET study. Hum Brain Map 27:153-161. CrossRef Medline

Klein D, Mok K, Chen JK, Watkins KE (2014) Age of language learning shapes brain structure: a cortical thickness study of bilingual and monolingual individuals. Brain Lang 131:20-24. CrossRef Medline

Kolb B, Forgie M, Gibb R, Gorny G, Rowntree S (1998) Age, experience and the changing brain. Neurosci Biobehav Rev 22:143-159. CrossRef Medline

Lenneberg EH (1967) The biological foundations of language. New York: Wiley.

Lewis CM, Baldassarre A, Committeri G, Romani GL, Corbetta M (2009) Learning sculpts the spontaneous activity of the resting human brain. Proc Natl Acad Sci U S A 106:17558-17563. CrossRef Medline

Marian V, Blumenfeld HK, Kaushanskaya M (2007) The Language Experience and Proficiency Questionnaire (LEAP Q): assessing language profiles in bilinguals and multilinguals. J Speech Lang Hear Res 50:940-967. CrossRef Medline

McAvoy M, Mitra A, Coalson RS, d'Avossa G, Keidel JL, Petersen SE, Raichle ME (2015) Unmasking language lateralization in human brain intrinsic activity. Cereb Cortex piibhv007. Advance online publication. Retrieved Jan 30, 2015. doi: 10.1093/cercor/bhv007. CrossRef Medline

Mennes M, Kelly C, Zuo XN, Di Martino A, Biswal BB, Castellanos FX, Milham MP (2010) Inter-individual differences in resting-state functional connectivity predict task induced BOLD activity. Neuroimage 50: 1690-1701. CrossRef Medline

Moyer A (2007) Empirical consideration on the age factor in L2 phonology. Issues Appl Ling 15:109-127.

Murphy K, Birn RM, Handwerker DA, Jones TB, Bandettini PA (2009) The impact of global signal regression on resting state correlations: are anticorrelated networks introduced? Neuroimage 44:893-905. CrossRef Medline

Muschelli J, Nebel MB, Caffo BS, Barber AD, Pekar JJ, Mostofsky SH (2014) Reduction of motion-related artifacts in resting state fMRI using aCompCor. Neuroimage 96:22-35. CrossRef Medline

Neville H, Bavalier D (2002) Human brain plasticity: evidence from sensory deprivation and altered language experience. Prog Brain Res 138:177-88. CrossRef Medline

Penfield W, Roberts L (1959) Speech and brain mechanisms. Princeton, NJ: Princeton.

Saad ZS, Gotts SJ, Murphy K, Chen G, Jo HJ, Martin A, Cox RW (2012) 
Trouble at rest: how correlation patterns and group differences become distorted after global signal regression. Brain Connect 2:25-32. CrossRef Medline

Schlegel AA, Rudelson JJ, Tse PU (2012) White matter structure changes as adults learn a second language. J Cogn Neurosci 24:1664-1670. CrossRef Medline

Schön D, Magne C, Besson M (2004) The music of speech: music training facilitates pitch processing in both music and language. Psychophysiology 41:341-349. CrossRef Medline

Smith SM, Vidaurre D, Beckmann CF, Glasser MF, Jenkinson M, Miller KL, Nichols TE, Robinson EC, Salimi-Khorshidi G, Woolrich MW, Barch DM, Uğurbil K, Van Essen DC (2013) Functional connectomics from resting-state fMRI. Trends Cogn Sci 17:666-682. CrossRef Medline

Spreng RN, Stevens WD, Chamberlain JP, Gilmore AW, Schacter DL (2010) Default network activity, coupled with the frontoparietal controlnetwork, supports goal0directed cognition. Neuroimage 53:303-317. CrossRef Medline

Stoodley CJ, Valera EM, Schmahmann JD (2012) Functional topography of the cerebellum for motor and cognitive tasks: an fMRI study. Neuroimage 59:1560-1570. CrossRef Medline

Tzourio-Mazoyer N, Landeau B, Papathanassiou D, Crivello F, Etard O, Delcroix N, Mazoyer B, Joliot M (2002) Automated anatomical labeling of activations in SPM using a macroscopic anatomical parcellation of the MNI MRI single-subject brain. Neuroimage 15:273-289. CrossRef Medline

Ventura-Campos N, Sanjuán A, González J, Palomar-García MÁ, Rodríguez-
Pujadas A, Sebastián-Gallés N, Deco G, Ávila C (2013) Spontaneous brain activity predicts learning ability of foreign sounds. J Neurosci 33 : 9295-9305. CrossRef Medline

Vigneau M, Beaucousin V, Hervé PY, Jobard G, Petit L, Crivello F, Mellet E, Zago L, Mazoyer B, Tzourio-Mazoyer N (2011) What is righthemispheric contribution to phonological, lexico-semantic, and sentence processing? Insights from a meta-analysis. Neuroimage 52:577-593. CrossRef Medline

Vincent JL, Kahn I, Snyder AZ, Raichle ME, Buckner RL (2008) Evidence for a frontoparietal control system revealed by intrinsic functional connectivity. J Neurophysiol 100:3328-3342. CrossRef Medline

Wang D, Buckner RL, Liu H (2014) Functional specialization in the human brain estimated by intrinsic hemispheric interaction. J Neurosci 34: 12341-12352. CrossRef Medline

Wang Y, Kuhl PK, Chen C, Dong Q (2009) Sustained and transient language control in the bilingual brain. Neuroimage 47:414-422. CrossRef Medline

Wartenburger I, Heekeren HR, Abutalebi J, Cappa SF, Villringer A, Perani D (2003) Early setting of grammatical processing in the bilingual brain. Neuron 378:159-170. CrossRef Medline

Wechsler D (1981) Manual for the Wechsler Adult Intelligence ScaleRevised. San Antonio, TX: Psychological Corporation.

Whitfield-Gabrieli S, Nieto-Castanon A (2012) Conn: a functional connectivity toolbox for correlated and anticorrelated brain networks. Brain Connect 2:125-141. CrossRef Medline 